\title{
Quality of Samples in Adhesive Joint Testing
}

\author{
Józef Kuczmaszewski', Magdalena Zawada-Michałowska1* \\ 1 Department of Production Engineering, Faculty of Mechanical Engineering, Lublin University of Technology, \\ Nadbystrzycka 36, 20-618 Lublin, Poland \\ * Corresponding author's e-mail: m.michalowska@pollub.pl
}

\begin{abstract}
The study attempts to assess the quality of various types of samples used in the adhesive joint testing. One great weakness of the scientific research conducted on this type of joints is that the published papers generally do not include an analysis of the samples quality. Although the standards define the tolerances of individual dimensions, detailed reports are in fact rarely presented. Above all, it is very important to control the thickness of the adhesive, which significantly affects the strength of adhesive bonds. It was found that obtaining high quality samples depends mainly on observing the technological discipline and using appropriate instrumentation. The paper presents the standards that should be a reliable model for the scientific research on adhesive joints.
\end{abstract}

Keywords: adhesive joints, quality, aviation, sample preparation.

\section{INTRODUCTION}

The aviation industry sets high expectations for adhesive joints. This is primarily due to the safety reasons and the need to ensure reliability for aircraft. The adhesive joint tests are conducted on the basis of the relevant global standards and additional guidelines, defined internally by individual aviation companies. Research is carried out based on the recommended sample geometry, which explains why the repeatability and accuracy of the geometric features is so important. Obtaining high quality samples requires appropriate technologies of their execution.

As it is commonly known, the properties of adhesive joints, especially their strength, are closely correlated with their geometric characteristics, mainly in the bonding zone. Geometric dimensions, and in particular the thickness of the adhesive layer and its even distribution, the resulting flash and any other change in the bonding zone, play a major part. Other key factors include the technological conditions and their repeatability, such as curing temperature, value and distribution of pressure as well as the defects in the adhesive structure and adhesion zone. In this context, the results of the comparative tests on the quality of the adhesive or the quality of surface preparation are strongly dependent on the repeatability of structural features and technology $[1,2,8]$.

\section{ADHESIVE JOINTS}

Adhesive joints are classified as inseparable and direct joints. It is one of the most promising joining methods used in mechanical engineering. Adhesive bonding is defined as the joining of elements using an adhesive (a non-metallic substance of organic or inorganic origin). The effects of this process are determined by the phenomenon of adhesion, with all its complexity, and internal cohesion of the adhesive and the material [18, 22, 23, 29].

Adhesive bonding is a very complex process, so it is very difficult to predict the strength of a joint. The authors of papers $[9,16]$ indicate that the strength of adhesive joints is affected by the material, structural and technological factors. The most important material factors are the properties of the adhesive and of the materials being combined. The structural factors, depending on the 
structure of the adhesive joint, include: the length of the overlap and its bevelling, if any, the thickness of the adherends, the thickness and bevelling of laps, the thickness of the adhesive layer and the size of the flash $[15,19]$. The main technological factors involve: the surface preparation method, the way the adhesive is prepared and applied, as well as the temperature and pressure during the curing process. In addition, the operating factors such as the load nature and its duration, operating temperature, and chemical aggressiveness of the environment should also be taken into account. The bonding technology should be selected individually, depending on the materials of the bonded elements and the type of joint characterised by specific geometric features $[7 \div 9,16,20,27]$.

Selection of the right adhesive is also crucial in the design of adhesive joints. Adhesives are classified by joint strength into [9]:

- pressure-sensitive adhesives - low strength sufficient only for reversible bonding,

- assembly adhesives - medium strength allowing permanent bonding,

- structural adhesives - high strength enabling structural connections - widely used in mechanical engineering.

Adhesive bonding has many advantages, for example: reduction of the structure weight, low unit costs, no need to make holes or use fasteners, uniform distribution of stresses, no interference in the structure of the connected elements, possibility of bonding materials with different properties [2], possible use with other bonding methods (hybrid joint) [3], good sealing properties, protection against moisture, protection against corrosion as well as ability to dampen vibrations [5, 12, 14, 23, 28].

The disadvantages of adhesive joints include mainly: limited resistance to increased temperature, the need of using additional operations related to, for example, surface preparation, low joint control possibilities and proclivity to delamination $[6,14,23,25,26]$.

Adhesive joints enable bonding both small elements (electronics) and large structures (automotive, aviation industry). In the aviation and aerospace industries, adhesive bonding is a very desirable method due to the use of ultra-lightweight structures, which allows for a significant reduction in the manufacturing and operating costs. Moreover, adhesive bonding is an alternative to the widely used mechanical joints $[6,13,17,21,24]$.

\section{QUALITY OF ADHESIVE JOINTS}

According to ISO 8402 , the quality is "the totality of features and properties of a product or service that determine its ability to satisfy stated or implied needs' [31]. In the case of the adhesive joint quality, achieving the required accuracy of shape and dimensions will result in adequate strength and acceptable repeatability. The accuracy of shape and dimensions is one of the features of an adhesive joint that affect its strength. The authors of paper [11] define the quality of an object as 'a set of features belonging to this object'. In order to determine its quality, it is therefore important to establish certain characteristics, which are generally divided into measurable (quantities) and non-measurable (attributes) ones. In yet another paper, the authors [10] describe quality as follows:

- degree of approaching perfection,

- suitability for use,

- fulfilment of expectations,

- compliance with requirements.

When it comes to the quality of adhesive joints, if a joint meets the requirements for dimensional accuracy (measurable feature), this will translate into adequate strength (also measurable feature). However, if the structural requirements are not met, the strength will be significantly reduced.

The final quality assessment is based on the measurement results and the appropriate qualification of the features. Still, only some aspects of quality are measured, and not the quality itself. In the case of adhesive joints, a number of factors are subject to inspection, both in terms of preparation and the joints that have been made. This paper is focused on the dimensional accuracy $[4,10,11]$.

One of the concepts of quality management is to meet the established patterns that are adopted or created on the basis of standards or other recognised external documents. These documents contain the requirements that must be met in order for the quality management system to be considered as conforming to them. In general, there are no regulations that force companies to apply such standards. However, the lack of possibility to authenticate the implemented quality management system makes certification difficult or even impossible. Therefore, companies all over the world follow the relevant global standards and often define additional internal guidelines $[10,11]$. 

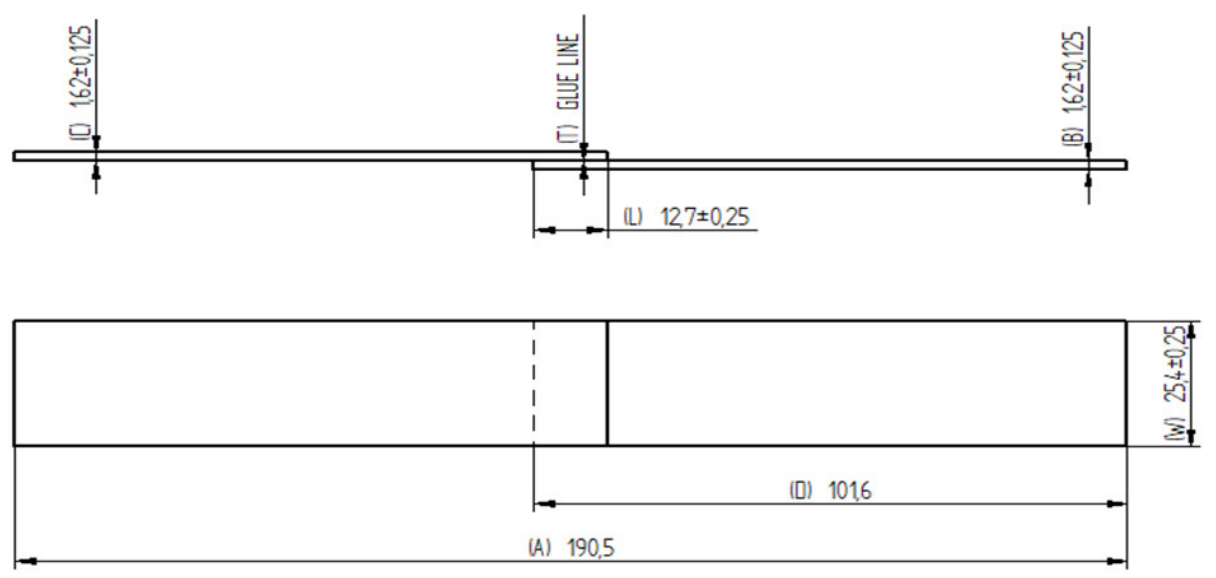

Fig. 1. Single overlap joint for shear strength testing 'Single Overlap' [32]

\section{TYPES OF ADHESIVE JOINTS AND ACCURACY STANDARDS}

The quality of samples was analysed for the following adhesive joints:

- single overlap joint for shear strength testing 'Single Overlap' - in accordance with ASTM D1002-10, configuration: EN AW-2024 aluminium alloy - EN AW-2024 aluminium alloy (Fig. 1),

- joint for peel resistance of adhesives test 'TPeel' - in accordance with ASTM D1876-08, configuration: EN AW-2024 aluminium alloyEN AW-2024 aluminium alloy (Fig. 2),

- double overlap joint for strength properties determination 'Double-Overlap' - in accordance with ASTM D3528-96, configurations: EN AW-2024 aluminium alloy - CFRP, CFRP - CFRP, technologies: secondary bonding, cobonding, co-curing (Fig. 3),
- thick-adherend metal lap-shear joints for determination of the stress-strain behaviour of adhesives 'Metal Thick-Adherend' - in accordance with ASTM D5656-10, configuration: EN AW-2024 aluminium alloy - EN AW-2024 aluminium alloy (Fig. 4).

All the tested adhesive joints were made and then measured in compliance with the international ASTM standards. It is worth noting that the rather narrow tolerances of some dimensions make appropriate instrumentation necessary for the production of test samples. The photographs of the samples in many publications show that the sample quality often does not meet the requirements. This results in a greater dispersion of strength in destructive tests, and sometimes in a significant reduction in the potential possibility of the adhesive.

Each of the joints shown can be made in two ways, either individually, where the size of the adherend corresponds to one sample, or as a panel,

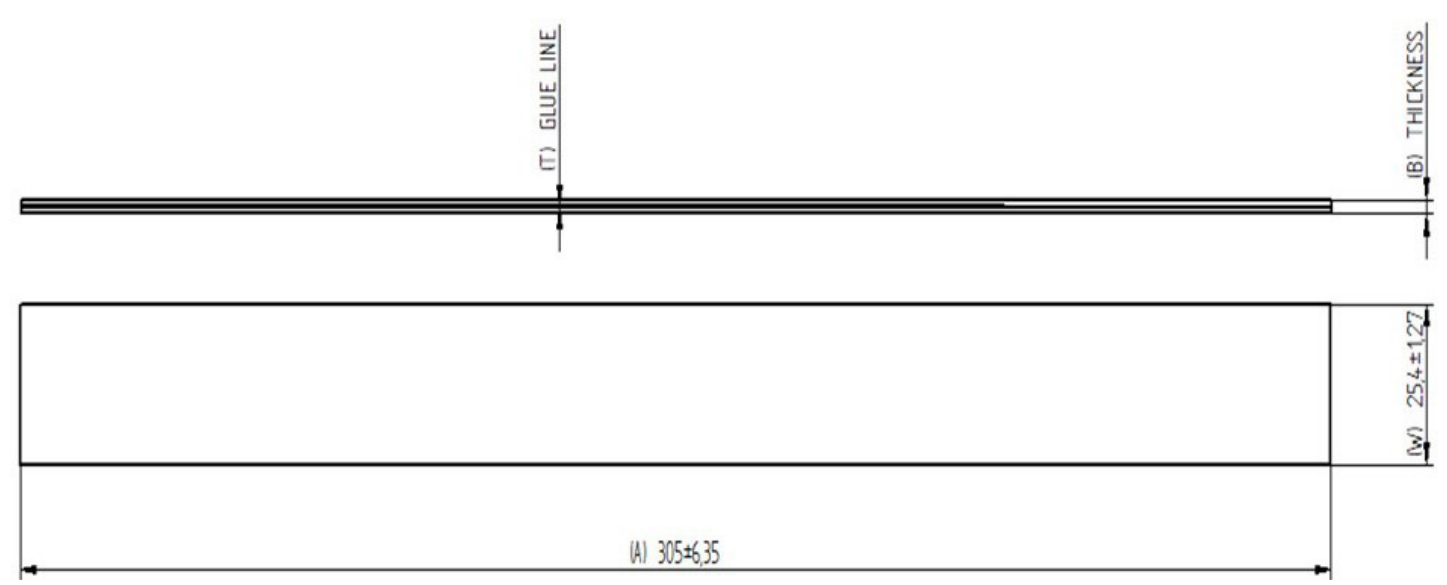

Fig. 2. Joint for peel resistance of adhesives test 'T-Peel' [33] 

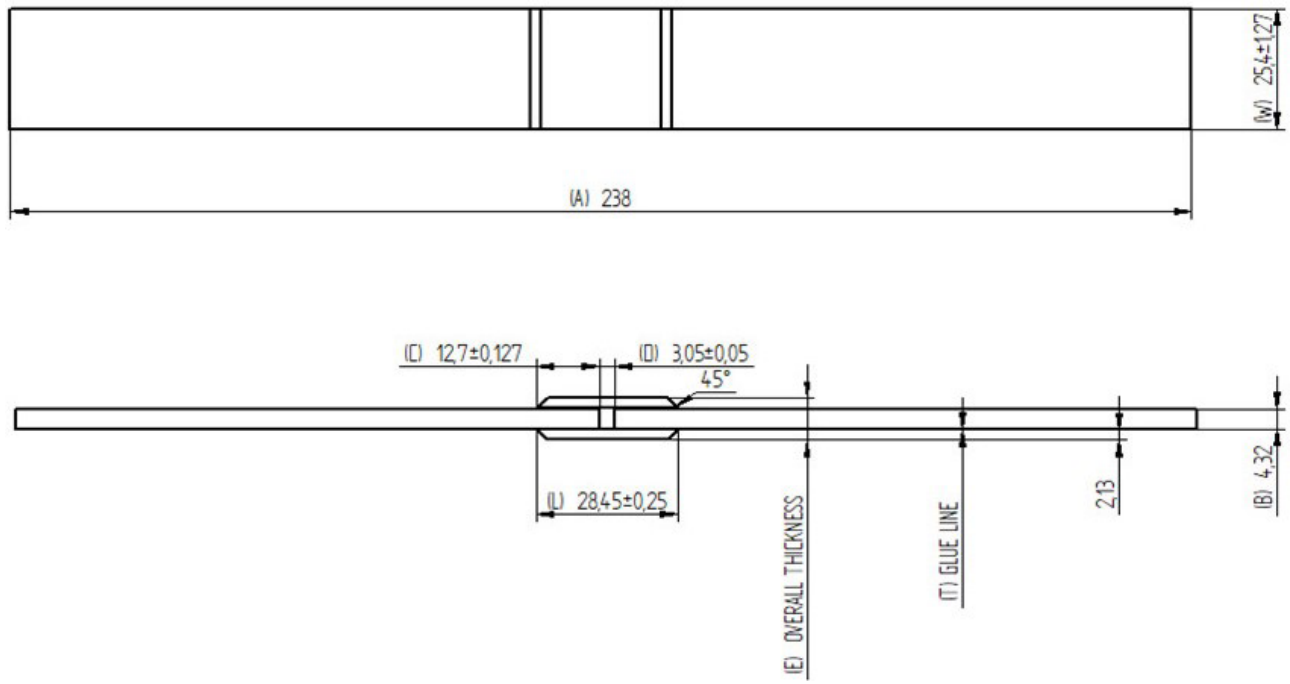

Fig. 3. Double overlap joint for strength properties determination 'Double-Overlap' [34]

where after bonding the materials, it is necessary to carry out a cutting process to obtain individual samples with the necessary finish. When deciding on a particular option, the advantages and disadvantages of different technologies must be taken into account. 1. Single-sample technology:

- difficulties in the determination of adherends, the need to make special instrumentation,

- relative ease to obtain the required clamping pressure,

- flashes appear not only along the overlap (or lap) length, but also at the side edges,

- difficulty in maintaining the same adhesive thickness in all samples.

2. Panel technology:

- difficulties in achieving the appropriate pressure due to the large adhesive surface, the pressure under vacuum conditions is in many cases too low (up to $0.1 \mathrm{MPa}$ ),

- adhesive is applied onto all samples at the same time, i.e. in the same state of curing, which is an important advantage,

- the variety of the thickness of the adhesive layer in individual samples, after the panels are cut, is smaller,

- due to the lack of perpendicularity of the cutting line, when using water jet cutting, the samples with thick adherends must be additionally processed (usually by milling),

- an autoclave or press with the right pressure is necessary to ensure the adequate clamping pressure.

The analysis of the advantages and disadvantages of the respective technologies clearly shows
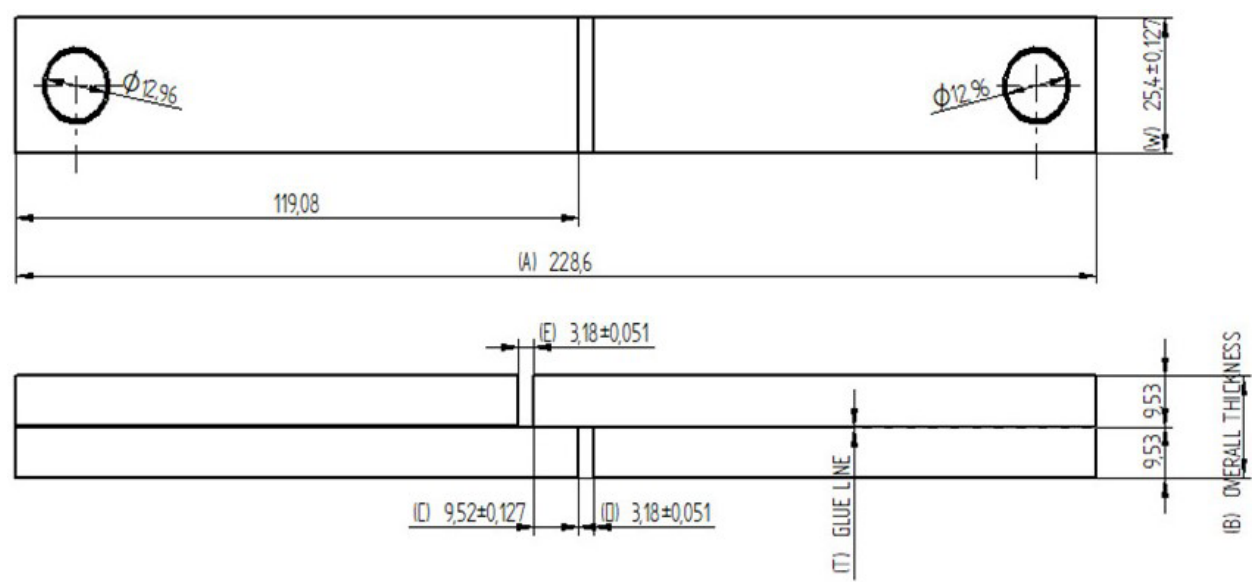

Fig. 4. Thick-adherend metal lap-shear joints for determination of the stressstrain behaviour of adhesives 'Metal Thick-Adherend' [35] 


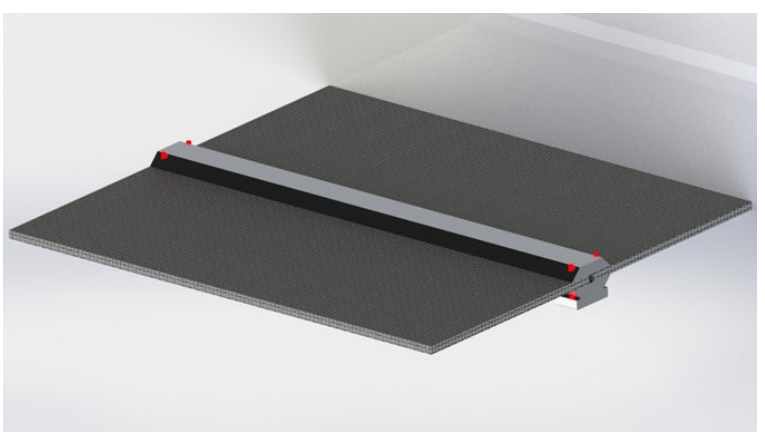

Fig. 5. Panel technology

that the preferred technology is to bond panels (Fig. 5) and then produce samples through cutting and machining (where necessary).

The correct preparation of samples requires the development of appropriate own technologies, which included the following elements for each configuration:

- cutting sheets or plates to panel size,

- surface preparation according to the program and using the approved procedure,

- research of surface topographic and energy features (2D/3D topography, scanning microscopy, atomic force microscopy, SEP),

- joining the panels using own procedure,

- cutting the panels into samples,

- non-destructive testing (NDT),

- geometric features measurements of samples,

- static destructive tests in accordance with the programme (at different temperatures),

- statistical analysis.

Each sample should have an identification code developed for the test programme. The static strength testing, and in particular the analysis of the variety of this strength, are important measures related to the impact of the repeatability of the geometric features of the samples on the repeatability of the strength values.

\section{RESEARCH METHODOLOGY}

The study analysed the dimensional accuracy of the adhesive joints made with two-component epoxy adhesive in form of paste and film adhesive. EN AW-2024 aluminium alloy and a CFRP were used.

For a thickness of $4.32 \mathrm{~mm}$, the composite was made of 32 layers, while the $2.16 \mathrm{~mm}$ composite incorporated 16 layers.
The requirements for the level of precision of measuring instruments and dimension tolerance were taken into account. A Keyence VHX-5000 optical digital microscope was used to examine the selected geometric features of the prepared samples presented in the paper.

Other values, not presented in this paper (e.g. total length, overlap width, etc.), were measured with basic measuring tools, i.e.: a slide caliper and a micrometer.

\section{ANALYSIS OF THE QUALITY OF THE OBTAINED SAMPLES}

For 'Single Overlap' samples (Fig. 1), the important dimensions are primarily: the thickness of the adhesive layer and the length of the overlap. Figure 6 presents the results of measurement of the adhesive joint thickness, while Figure 7 shows the results of the measurement of overlap length for the samples produced in the panel technology.

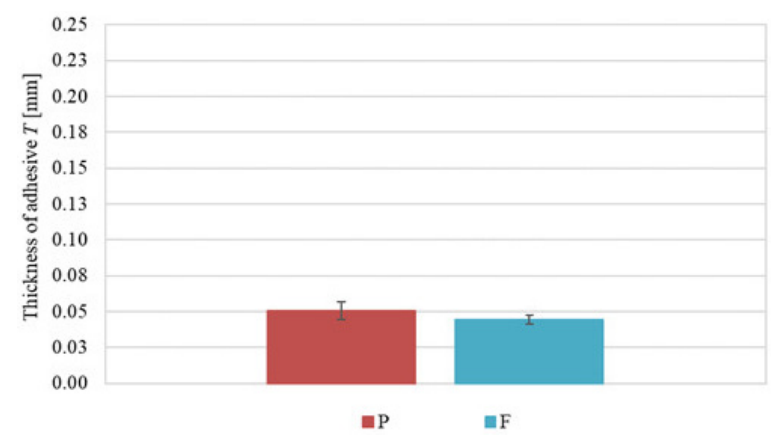

Fig. 6. Adhesive joint thickness measurement results for 'Single Overlap' samples, panel technology, P paste adhesive, $\mathrm{F}$ - film adhesive, pressure: $0.1 \mathrm{MPa}$

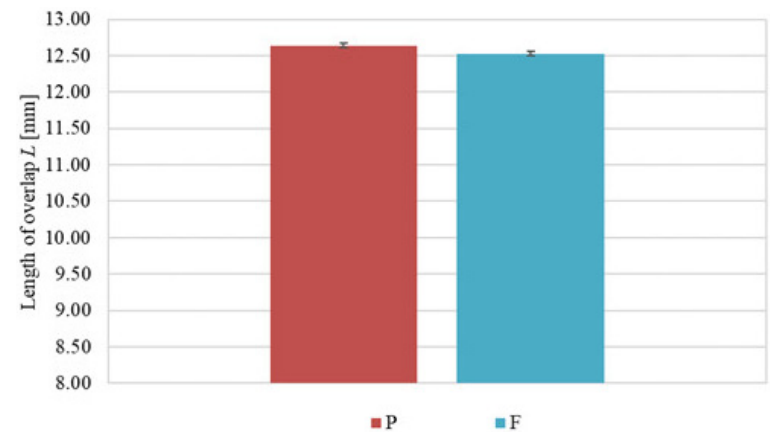

Fig. 7. Overlap length measurement results for 'Single Overlap' samples, panel technology, P - paste adhesive, F - film adhesive, pressure: $0.1 \mathrm{MPa}$ 


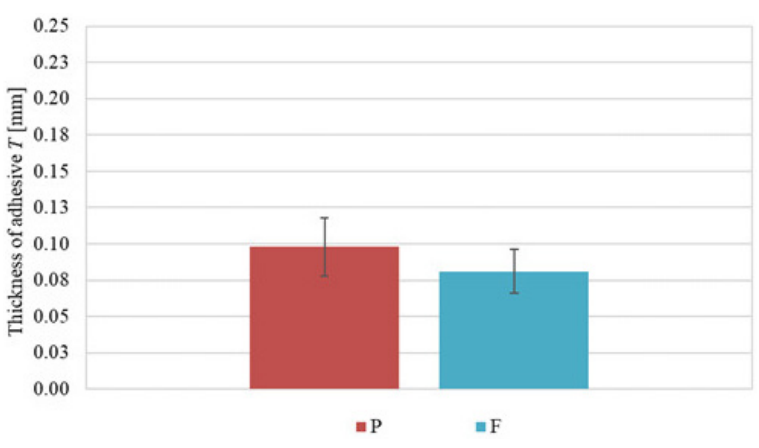

Fig. 8. Adhesive joint thickness measurement results for 'Single Overlap' samples, single-sample technology, $\mathrm{P}$ - paste adhesive, $\mathrm{F}-$ film adhesive, pressure: $0.1 \mathrm{MPa}$

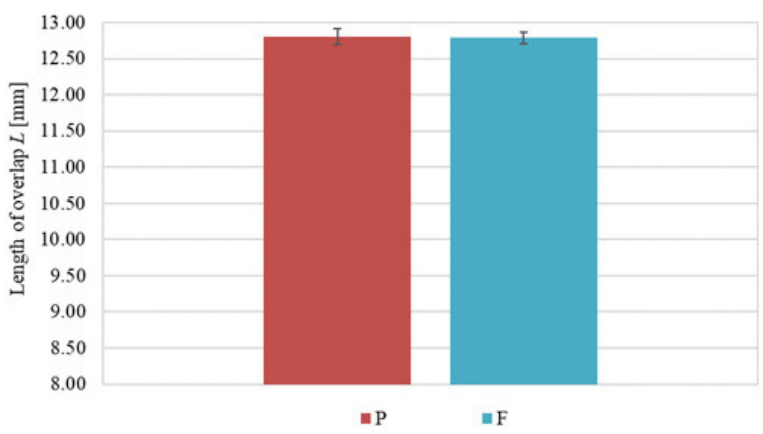

Fig. 9. Adhesive joint thickness measurement results for 'Single Overlap' samples, single-sample technology, $\mathrm{P}$ - paste adhesive, $\mathrm{F}$ - film adhesive, pressure: $0.1 \mathrm{MPa}$

The obtained values were compared with the calculated spread (standard deviation).

It is worth noting that the use of paste adhesive is associated with a slightly greater spread $(\delta$ $=0.006 \mathrm{~mm}$ ) of the adhesive layer thickness (Fig. 6 ) than the use of film adhesive $(\delta=0.003 \mathrm{~mm})$. The results of the overlap length measurement (Fig. 7) showed a very small spread - using the panel technology gave very good results.

Figures 8 and 9 show the results of the measurements of adhesive joint thickness and overlap length, respectively, for the samples obtained through the single-sample technology.

A comparison of the results of measurements of adhesive thickness and overlap length for the samples produced in the panel technology (Figs. 6 and 7) and as single samples (Figs. 8 and 9) revealed that smaller spreads were obtained in the panel technology regardless of the adhesive used. The following spreads were obtained in an analysis of adhesive thickness and the tested adhesives: for paste adhesive $\delta=0.006 \mathrm{~mm}$ for panel technology and $\delta=0.020 \mathrm{~mm}$ for single-sample technology, as well as for film adhesive $\delta=0.003 \mathrm{~mm}$ for panel technology, $\delta=0.015 \mathrm{~mm}$ for singlesample technology. Similar relationships were obtained for the overlap length.

In the further part of the paper, the results of geometric features measurements were analysed only for the panel technology.

The most important geometric feature in the 'T-Peel' samples (Fig. 2) is the thickness of the adhesive layer. The measurement results with the spread are shown in Figure 10.

In the case of the 'T-Peel' samples (Fig. 10), the spread of the thickness of the paste adhesive $(\delta=0.017 \mathrm{~mm})$ was comparable to that of a film adhesive $(\delta=0.015 \mathrm{~mm})$. The adhesive surface is much larger in comparison to the 'Single Overlap' sample. This led to a significant increase in adhesive thickness and an increased spread thereof at the same clamping pressure.

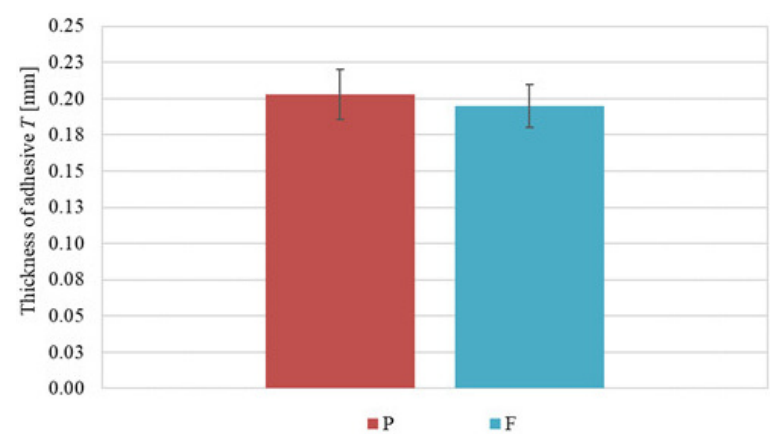

Fig. 10. Adhesive joint thickness measurement results for 'T-peel' samples, panel technology, $\mathrm{P}$ - paste adhesive, F - film adhesive, pressure: $0.1 \mathrm{MPa}$

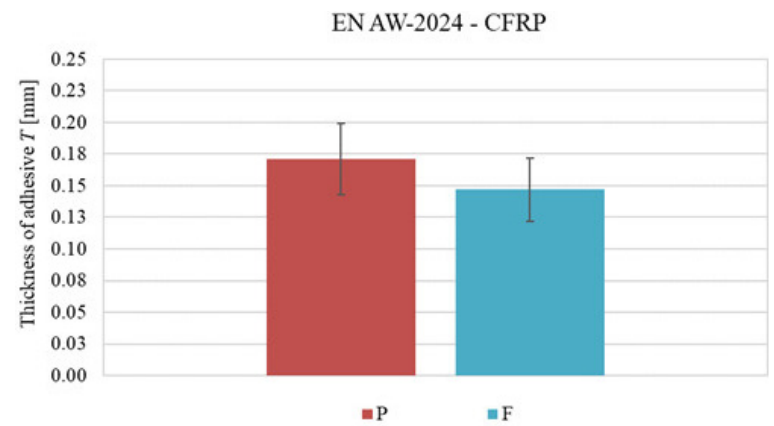

Fig. 11. Adhesive thickness measurement results for 'Double Overlap' sample - material configuration: EN AW-2024 aluminium alloy - CFRP, P - paste adhesive, $\mathrm{F}$ - film adhesive, pressure: $0.1 \mathrm{MPa}$, secondary bonding technology 


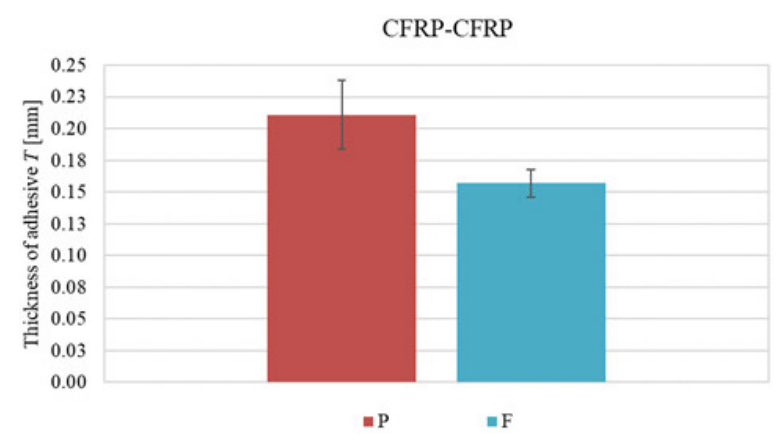

Fig. 12. Adhesive thickness measurement results for 'Double Overlap' sample - material configuration: CFRP - CFRP, $\mathrm{P}$ - paste adhesive, $\mathrm{F}$ - film adhesive, pressure: $0.1 \mathrm{MPa}$, secondary bonding technology

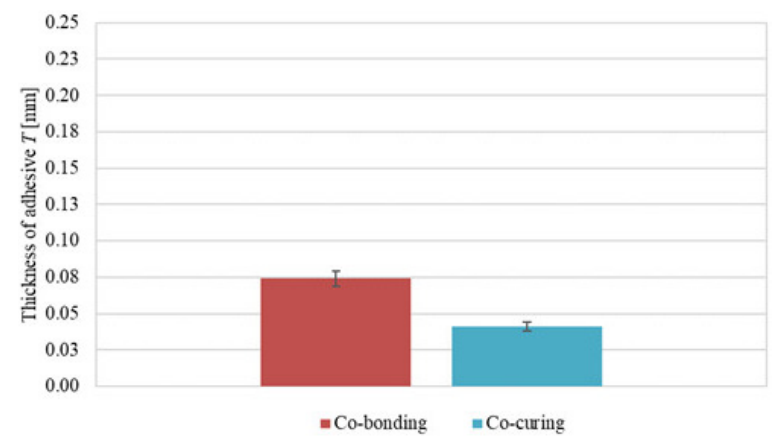

Fig. 13. Adhesive thickness measurement results for a Double Overlap' sample - material configuration: CFRP - CFRP, pressure: 0.1 $\mathrm{MPa}$, co-bonding and co-curing technologies

The 'Double Overlap' samples are important from the research point of view (Fig. 3). The repeatability of the adhesive area on each of the laps and the thickness of the adhesive layer are essential. In the secondary bonding technology, two material configurations were made: EN AW-2024 aluminium alloy-CFRP, and CFRP-CFRP. Figures 11 and 12 show the results of the measurement of adhesive thickness for two material configurations together with the calculated spread.

The 'Double Overlap' samples are difficult to make. As shown in Figure 3, the crucial factors include frontal adherend separation, appropriately bevelled laps as well as the bonding area length of the adherends and lap. It is important to observe the $12.7 \mathrm{~mm}$ dimension with a tolerance of $0.254 \mathrm{~mm}$. This has a certain impact on the spread of adhesive thickness (Fig. 11). The quality of the samples in this case depends on the instrumentation used and the know-how of the operator. In the EN AW-2024-CRFP configuration the spread is comparable $(\delta=0.028 \mathrm{~mm}$ for paste adhesive and $\delta=0.025 \mathrm{~mm}$ for film adhesive).

For the CFRP-CFRP configuration (Fig. 12), a significantly higher spread was observed for the joints made with paste adhesive $(\delta=0.027 \mathrm{~mm}$ for paste adhesive, $\delta=0.011 \mathrm{~mm}$ for film adhesive), and the average adhesive thickness was significantly lower for film adhesive.

The 'Double Overlap' samples were also prepared using two other technologies, i.e. cobonding and co-curing, in which the CFRPCRFP configuration and film adhesive were used. Figure 13 shows a comparison of the measurement results of the adhesive joint thickness for the 'Double Overlap' joint and the two above-mentioned technologies.

As shown in Figure 13, adhesive thickness in the co-curing technology (simultaneous cure of the adherends and laps) is clearly lower than in the co-bonding technology (cured adherends, simultaneous cure of film adhesive and laps). In both technologies, the spread of the adhesive layer thickness is comparable.

The samples incorporating thick and rigid adherends are difficult to prepare (Fig. 4). Figure 14 shows an illustrative measurement photo of the 'Metal Thick-Adherend' sample taken using the Keyence microscope.

In this case, the flatness of the plates is also important, as it extensively determines the uniformity of the thickness of the adhesive layer. The thickness of the adhesive layer and the length of the overlap play a major part in such circumstances. Figure 15 shows the results of adhesive thickness measurements, and Figure 16 shows the results of the overlap length measurements.

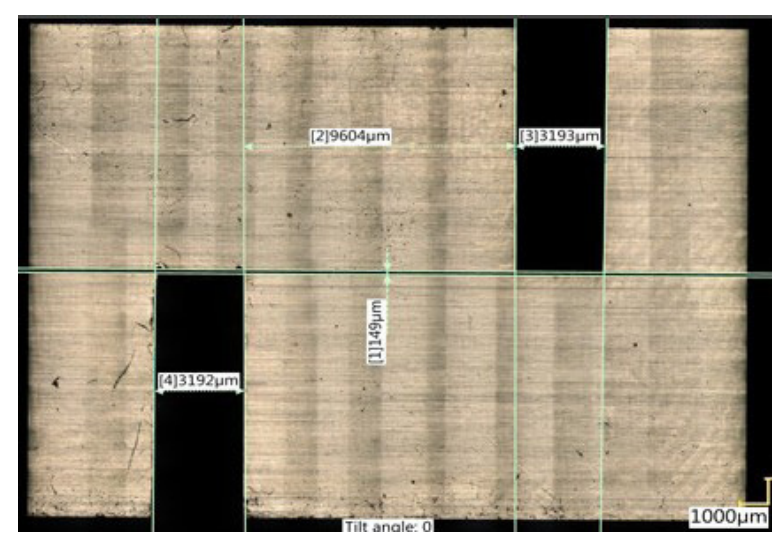

Fig. 14. An illustrative measurement photograph of the 'Metal Thick-Adherend' sample 


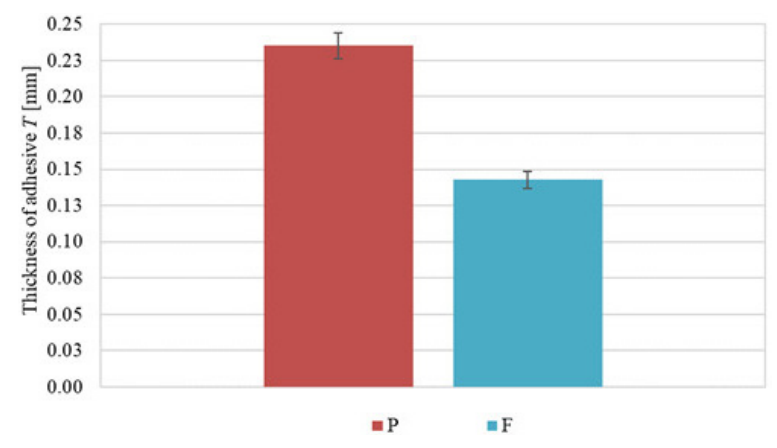

Fig. 15. Adhesive joint thickness measurement results for 'Metal Thick-Adherend' samples, panel technology, $\mathrm{P}$ - paste adhesive, $\mathrm{F}$ - film adhesive, pressure: $0.1 \mathrm{MPa}$

In the case of 'Metal Thick-Adherend' samples, a much greater spread $(\delta=0.009 \mathrm{~mm})$ of the adhesive thickness (Fig. 15) was also observed for the joints made with paste adhesive. This type of joint is primarily used to test the properties of the adhesive in the cured state, especially the Kirchhoff G modulus, under the conditions close to pure shear. In this test, the adhesive thickness significantly affected the measurement results. For the joints made with film adhesive, the spread was significantly lower $(\delta=0.006 \mathrm{~mm})$. Such samples must be prepared with particular care, and the adherends must have a small flatness deviation. The proper adhesive application method is also important to ensure that the adhesive is distributed as evenly as possible over the entire bonding surface.

The results spread of overlap length (Fig. 16) for both forms of adhesive is comparable; the use of the appropriate instrumentation for sample cutting and processing is vital.

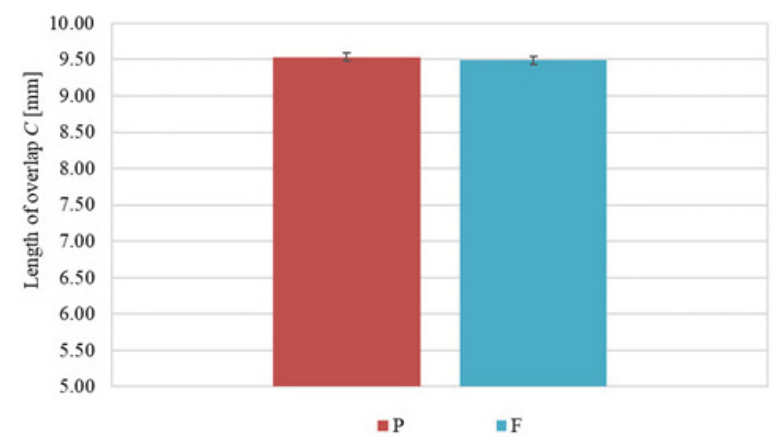

Fig. 16. Overlap length measurement results for 'Metal Thick-Adherend' samples, panel technology, P - paste adhesive, $\mathrm{F}$ - film adhesive, pressure: $0.1 \mathrm{MPa}$
The specially prepared measurement reports were used to collect the measurement results of the geometry of individual samples.

The obtained results suggested that the paste adhesive contributed to a greater thickness of adhesive joints. However, the indicated differences fall within the calculated spread. In addition, when analysing the co-bonding and co-curing technologies, which employed a film adhesive, a much smaller adhesive thickness and a smaller standard deviation were observed for co-curing.

\section{CONCLUSIONS}

The analysis of the quality of different types of adhesive joints allows the following conclusions to be drawn:

3 . The repeatability and accuracy of the geometric characteristics of the samples are essential in adhesive joints. Important geometric features are correlated with the test type, material configuration and sample type.

4. The strength of adhesive joints is significantly influenced by the thickness of the layer of cured adhesive, and therefore this value should be especially monitored in the adhesive bonding technology.

5. Appropriate technological discipline and specialised instrumentation are necessary in order to obtain the samples of good quality, corresponding to the tolerances defined in the quoted standards.

6. Specific measurements of the selected geometric features should be taken for each sample before they are qualified for testing, and the samples should be appropriately marked throughout the test cycle.

7. In the 'Double Overlap' sample technology, the frontal separation of the adherends is important (tolerance and no flashes at the front of the adherends), the separator used must be easily removable.

8. In the case of 'Metal Thick-Adherend' samples, special attention must be paid to the flatness of the adherends. This is a prerequisite for an acceptable spread of adhesive thickness.

9. It is easier to achieve a smaller spread of adhesive thickness for film adhesive in all material configurations.

10. The thickness of the adhesive layer, under the same pressure conditions, depends significantly on the adopted joining technology, 
about $80 \%$ greater thickness was obtained for co-bonding than co-curing.

11. As regards the 'Metal Thick-Adherend' samples, i.e. joints with high bending stiffness, the obtained adhesive thickness was approximately $60 \%$ higher for a paste adhesive than that produced by a film adhesive under the same curing conditions.

12.In the case of 'Metal Thick-Adherend', greater about $65 \%$ thickness of the adhesive layer was obtained for adhesive in the form of paste than for film adhesive.

13. Smaller spreads (in the range of $200 \%$ to $400 \%$ ) were obtained in the case of the panel technology as compared to the single sample technology, regardless of the adhesive used.

The research carried out shows that the accuracy of the test samples used in research on adhesive joints is a function of many factors. The knowledge of those factors and application of appropriate solutions in the field of technology and instrumentation design enable meeting the most demanding conditions defined in standards, and sometimes also additional requirements specified, for example, by aviation companies.

\section{REFERENCES}

1. Anasiewicz K., Kuczmaszewski J. Effect of Abrasive Waterjet Peening Surface Treatment of Steel Plates on the Strength of Single-Lap Adhesive Joints. Advances in Science and Technology Research Journal, 11(3), 2017, 270-276.

2. Barnes I T.A., Pashby I.R. Joining techniques for aluminium spaceframes used in automobiles: Part II - adhesive bonding and mechanical fasteners. Journal of Materials Processing Technology, 99(13), 2000, 72-79.

3. Bartczak B., Mucha J., Trzepieciński T. Stress distribution in adhesively-bonded joints and the loading capacity of hybrid joints of car body steels for the automotive industry. International Journal of Adhesion and Adhesives, 45, 2013, 42-52.

4. Bożek M., Kujawińska A., Rogalewicz M., Diering M., Gościniak P., Hamrol A. Improvement of catheter quality inspection process. MATEC Web of Conferences, 121, 2017, 1-8.

5. Brotherhood C.J., Drinkwater B.W., Dixon S. The detectability of kissing bonds in adhesive joints using ultrasonic techniques. Ultrasonics, 41(7), 2003, 521-529.

6. Ciardiello R., Belingardi G., Martorana B., Brunella V. Physical and mechanical properties of a re- versible adhesive for automotive applications. International Journal of Adhesion and Adhesives, 89, 2019, 117-128.

7. Da Silva L.F.M., Rodrigues T.N.S.S., Figueiredo M.A.V., de Moura M.F.S.F., Chousal J.A.G. Effect of Adhesive Type and Thickness on the Lap Shear Strength, Journal of Adhesion, 82(11), 2006, 1091-1115.

8. Ghumatkar A., Budhe S., Sekhar R., Banea M.D., De Barros S. Influence of adherend surface roughness on the adhesive bond strength. Latin American Journal of Solids and Structures, 13(13), 2016, 2356-2370.

9. Godzimirski J. Problemy klejenia konstrukcyjnego. Technologia i Automatyzacja Montażu, 1, 2009, 25-31.

10. Hamrol A. Zarządzanie jakością z przykładami. Wydawnictwo Naukowe PWN, Warszawa, 2008.

11. Hamrol A., Mantura W. Zarządzanie jakością. Teoria i praktyka. Wydawnictwo Naukowe PWN, Warszawa, 2005.

12. Hennemann K.K., Lenz D.M. Structural methacrylate/epoxy based adhesives for aluminium joints. International Journal of Adhesion and Adhesives, 89, 2019,11-18.

13. Higgins A. Adhesive bonding of aircraft structures. International Journal of Adhesion and Adhesives, 20, 2000, 367-376.

14. Hulimka J., Kałuża M. Preliminary Tests of Steelto-steel Adhesive Joints. Procedia Engineering, 172, 2017, 385-392.

15. Kafkalidis M.S., Thouless M.D. The effects of geometry and material properties on the fracture of single lap-shear joints. International Journal of Solids and Structures, 39(17), 2002, 4367-4383.

16. Kłonica M. Analysis of the effect of selected factors on the strength of adhesive joints. IOP Conference Series: Materials Science and Engineering, 2018, 393.

17. Komorek A., Godzimirski J., Pietras A. Numerical Analysis of Impact Loading of Adhesive Joints. Advances in Materials Science and Engineering, 2017, 1-10.

18. Kuczmaszewski J. Fundamentals of metal-metal adhesive joint design. Politechnika Lubelska, Lublin, 2006.

19. Kuczmaszewski J., Domińczuk J. Modelling of adhesive joints and predicting their strength with the use of neural networks. Computational Materials Science, 43(1), 2008, 165-170.

20. Łubkowski D. Badania wytrzymałości na odrywanie połączeń klejowych: tworzywo polimero-we/metal. Przetwórstwo Tworzyw, 15(4), 2009, 156-160.

21. Machado J.J.M., Nunes P.D.P., Marques E.A.S., da Silva L.F.M. Adhesive joints using aluminium and CFRP substrates tested at low and high temperatures under quasi-static and impact conditions for the automotive industry. Composites Part B: Engi- 
neering, 158, 2019, 102-116.

22. Mascaro B., Budzik M.K., Castaings M., Jumel J., Shanahan M.E.R. Evaluation of adhesive bond Young's modulus during crosslinking using a mechanical method and an ultrasound method. Journal of Physics: Conference Series, 2012, 353.

23. Mirski Z., Piwowarczyk T. Podstawy klejenia, kleje i ich właściwości. Przegląd Spawalnictwa: Klejenie, 8, 2008, 12-21.

24. Mirski Z., Piwowarczyk T. Wybrane aspekty technologii klejenia w produkcji autobusów. Przegląd Spawalnictwa: Klejenie, 8, 2008, 44-45.

25. Rośkowicz M. Wybrane problem długotrwałej eksploatacji połączeń klejowych. Problemy Eksploatacji, 3, 2006, 91-106.

26. Rudawska A. Przygotowanie powierzchni do klejenia wybranych materiałów konstrukcyjnych. Politechnika Lubelska, Lublin, 2017.

27. Sadowski T., Nowicki M., Pietras D., Golewski P. Gradual degradation of a thin-walled aluminum adhesive joint with omega cross section under bending. International Journal of Adhesion and Adhesives, 89, 2019, 72-81.

28. Scarselli G., Corcione C., Nicassio F., Maffezzoli A. Adhesive joints with improved mechani- cal properties for aerospace applications. International Journal of Adhesion and Adhesives, 75, 2017, 174-180.

29. Song J.H., Lim J.K. Bonding Strength in Structural Adhesive Bonded Joint. Metals and Materials International, 7(5), 2001, 467-470.

30. Xu L., Peng X., Pavur R., Prybutok V. Quality management theory development via meta-analysis. International Journal of Production Economics, 229, 2020, 1-16.

31. ISO 8402:1994 Quality management and quality assurance - Vocabulary.

32. ASTM D1002-10 Standard Test Method for Apparent Shear Strength of Single-Lap-Joint Adhesively Bonded Metal Specimens by Tension Loading (Metal-to-Metal).

33. ASTM D1876-08 Standard Test Method for Peel Resistance of Adhesives (T-Peel Test).

34. ASTM D3528-96 Standard Test Method for Strength Properties of Double Lap Shear Adhesive Joints by Tension Loading.

35. ASTM D5656-10 Standard Test Method for ThickAdherend Metal Lap-Shear Joints for Determination of the Stress-Strain Behavior of Adhesives in Shear by Tension Loading. 